placements up to 6 months. If the exchange trainee wants to be involved with research, links have been established with the Institute of Psychiatry and the Royal College of Psychiatrists. These projects can form the basis of continuing links between the UK and Latin America.

\section{Towards developing community working}

We are formulating a project for the development of community workers in Ecuador. We aim to train staff to monitor and follow up patients in the community. The longer-term objective is to support, train and supervise past service users so that they can become leaders of the rehabilitation process. They will lead the next group of service users in their passage of integration into the community. We would hope to use this process as a way to promote equality and tackle stigma, involving carers, family and workers as far as possible. Our goal is improved quality and autonomy of life for individuals with mental illness. There are five elements to the proposed community rehabilitation service:

- Using the new 'attention' model of rehabilitation, patients will receive a psychosocial diagnosis of their rehabilitation potential after 3 months of contact with the service.

- The service users will be provided with detailed multidisciplinary rehabilitation plans.

- Goals will be determined and set for short-, medium- and long-term rehabilitation. This will enable the selection of the appropriate candidates for integration into pre-employment, employment and supported accommodation.

- Our main intervention will be at the level of training professionals to determine when service users are ready to be reintegrated into the community, using evidence-based assessments that will predict the outcome of the rehabilitation process. We will create a training programme for workers, who will include nurses, assistants and social workers, to help them to monitor the progress of service users in the community and to build the new 'attention' model of rehabilitation, one that is not currently available in Ecuador.

- We will include psychoeducation and family interventions in the multidisciplinary rehabilitation system.

\section{Conclusion}

Our goal is that the links we create will actively enhance high-quality education and training in mental health in both South America and Europe.

\section{References}

Alarcón, R. D. (2002) Salud mental en América Latina, circa 2001 2002. [Mental health in Latin America, circa 2001-2002.] In Salud panamericana en el siglo XXI: fortalecimiento de la cooperación internacional y desarrollo de capital humano (ed. J. Sepûlveda), pp. 114-126. Instituto Nacional de Salud Pública.

Brazilian Ministry of Health (2005) Reforma Psiquiátrica e Politica de Saude Mental no Brasil. Ministerio de Saude.

Fiestas, F., Gallo, C. \& Poletti, G. (2008) What challenges does mental and neurological health research face in Latin American countries? Revista Brasileira de Psiquiatria, 30, 328-336.

Levav, I., Restrepo, H. \& Guerra de Macedo, C. (1994) The restructuring of psychiatric care in Latin America: a new policy for mental health services. Journal of Public Health Policy, 15, 71-85.

World Health Organization (2011a) Atlas - Psychiatric Training and Education Across the World. WHO.

World Health Organization (2011b) Mental Health Atlas. Department of Mental Health and Substance Abuse, WHO.

\section{THEMATIC PAPER}

\title{
Innovations in mental health training - the Kintampo Project, Ghana
}

\author{
Mark Roberts, ${ }^{1}$ Emmanuel Teye Adjase ${ }^{2}$ and Jim Crabb ${ }^{3}$
}

${ }^{1}$ Consultant Psychiatrist, Kintampo Project Lead (UK) Southern Health NHS Foundation Trust, UK

${ }^{2}$ Kintampo Project Lead (Ghana), Director of the Kintampo Rural Health Training School

${ }^{3}$ Consultant Psychiatrist and Honorary Senior Clinical Lecturer, Institute of Health \& Wellbeing, University of Glasgow, UK, email enquiries@thekintampotrust.org
The landscape of some low- and middle-income countries is sadly all too often littered with the remains of well intentioned health development projects that have failed. The Kintampo Project in Ghana is an education intervention that is set to achieve the most elusive of outcomes in development work, namely genuine sustainability. This article focuses on the challenges faced by the project and the factors that have allowed it to reach its targets.

\section{Background}

Until recently only $2 \%$ of people with a mental illness in Ghana, West Africa, received treatment or assessment by health services, as there were only around 18 psychiatrists and 1177 other trained mental health workers for the whole country of 24 million people (Roberts et al, 2013). A high-income country (e.g. the UK) would expect nearer 24000 such workers for 24 million people. Ghana now has a growing health budget but has nevertheless experienced a doctor and nurse 'brain drain'. 
Concerns about human rights abuses and the emergence of increasingly Western disease profiles have focused the country on improving mental health services. In 2007 the Ghana government resolved to strengthen community services by developing two new types of middle-level mental health worker, the clinical psychiatric officer (CPO) (initially called the medical assistant psychiatry, MAP) and the community mental health officer (CMHO). The CPO performs a similar role to district-level psychiatrists and the CMHO works with community psychiatric nurses (CPNs) and acts as a bridge with primary care. They cost less to train than doctors and nurses. The new roles also provide specialist career opportunities to improve workforce retention. Those trained in the new roles should be less likely than doctors and nurses to leave for work abroad, as their knowledge and skills are specifically designed for best practice in their own country.

\section{Project set-up}

This led to the Kintampo Project, a partnership since 2007 between Southern Health NHS Foundation Trust (formerly Hampshire Partnership NHS Foundation Trust), UK, and the College of Health and Wellbeing, Kintampo (CoHK) (formerly the Kintampo Rural Health Training School). The partnership was formed to develop mental health education programmes for CPOs and CMHOs.

The project has focused on three key interconnected areas:

- service needs (providing for the mental health needs of ill people)

- workforce requirements (the types and projected numbers of staff required to meet the needs)

- the educational needs of staff.

Although a mental health initiative, the Kintampo Project has largely been an education intervention with mental health as the beneficiary.

\section{Project achievements}

Between 2011 and 2013 the Kintampo Project realised the following achievements:

\section{Box 1 Factors that have facilitated the success of the Kintampo Project}

- Political mandate for change in the host country

- Strong local champions for the project

- A single, accountable project lead in each country

- Being an education intervention with mental health as the beneficiary

- A strong focus on educational theory, driven by a culturally acceptable curriculum

- Educating of educators rather than undertaking direct teaching

- A strong focus on communications

- Successfully accessing funding

- A focus on project management and 'hard graft'
- it has increased the number of trained CMHOs by $96 \%$

- it has enabled an extra 86530 individuals to access mental health treatment in Ghana.

By 2017 the Kintampo Project will have produced the intended number of CMHOs for Ghana, which will be enough to bring the country to the level expected for its economic status. End-point objectives for the project include ensuring that supervision, continuing professional development and clinical governance structures are in place for the new workforce. Preparations are underway for the UK project team to withdraw in 2017, by which time the mental health system in Ghana will be fully recruiting, training and retaining the new workforce without outside assistance.

\section{Factors that have led to success}

The Kintampo Project has been very successful. Sometimes low- and middle-income countries are subject to the unilateral efforts of well intentioned health development projects but failure can occur owing to lack of alignment with government plans. Fortunately, this has not been the fate of the Kintampo Project. Factors that have led to success where other ventures have failed have included the following (see also Box 1):

- alignment with government plans from the outset

- exceptionally strong local sponsorship from the Ghana project lead, the Rector of the College of Health and Wellbeing, Kintampo, and his educational institution, which has a long-established track record of delivering community health programmes (this made the Kintampo Project credible in Ghana from the outset)

- the UK project lead previously lived and worked in Ghana as a front-line clinician for over 2 years, which meant authenticity and realism was instilled in project's UK partners from the outset

- an expert in education from the University of Winchester Faculty of Education helped to ensure a very robust curriculum development for the CPO and CMHO programmes throughout, which created the bedrock for the long-term sustainability of the programme

- an unrelenting focus on the educating of educators rather than direct teaching

- a UK volunteer expert in communications being involved from the outset, helping to drive awareness-raising and producing consistent, clear and accessible messages about the Kintampo Project

- the drafting and implementation of a new Ghana Mental Health Act (846 of 2012), which is now providing the structures and mechanisms for community mental health services (this has demonstrated the political will in Ghana for 
mental health to be as important as other areas of health).

The hard-pressed economy in Ghana has meant that the mental health service development tasked for the Kintampo Project was risky and needed innovation. The task was to design a training programme for health professionals that did not exist at the time. For this reason, the recruiting of the enthusiastic and respected Professor of Medical Education as a volunteer was critical to the success of the project.

\section{Curriculum development}

Curriculum development is an iterative process achieved by repeated cycles of consultation, agreement, refinement and redesign. The choice of education model was important and the project used a model described by Stenhouse (1975) in which the process of education is seen along a continuum of product, process and enquiry. This continuum has didactic lecture-type teaching at the product end and formative discovery-based approaches at the enquiry end. As practice in Ghana tends to be mainly 'product' oriented, the College of Health and Wellbeing, Kintampo, started the $\mathrm{CPO}$ and CMHO curricula in the process area, with a leaning towards enquiry. The College is keen to move further towards the enquiry method through gradual change. The enquiry approach has advantages in an environment where mental health educators are scarce and where the requirements of future practice are uncertain.

\section{Lessons from the project}

Development project volunteers can become overwhelmed when faced with heavy administration and management tasks, so finding individuals with an aptitude and appetite for these work areas has been core to the Kintampo Project's achievement of its objectives on time and within budget.

The Kintampo Project can be conceptualised as a 'programme' consisting of an extensive portfolio of projects. For any complex set of projects to succeed, clear leadership and direction with good project and programme management are critical. By their very nature, development projects attract volunteers who, not unreasonably, come and go, depending on their other commitments. This can mean that the projects and even the programme lose focus over time, leading ultimately to failure.
The Kintampo Project has had single strong and highly energetic leads in the UK and Ghana, who have set the direction of travel, and coordinated and overseen the entire process, and who have been accountable to their employers and the full team of volunteers for 'getting the job done'. At an early stage, the Kintampo Project leads produced a helpful one-page vision and project plan; it was then regularly updated and adapted (Roberts \& Adjase, 2013). This channelled the enthusiasm of volunteers into a coherent whole. The role of programme leader is demanding and in practice has been equivalent to an extra full-time job for the UK lead, albeit one that is unpaid. The commitment must be there for the duration of the development project (in this case spanning several years). Without this role it is likely that the Kintampo Project would not have managed to achieve its considerable success.

The Kintampo Project established an exit point from day 1. Theoretically, every development project should be working towards putting itself out of business, aiming for the local population to manage their own affairs independently, without the assistance of outsiders. This is best achieved by clearly stating at the outset the objectives and when they are to be completed, and by committing to a time for withdrawal.

\section{Conclusions}

The Kintampo Project has achieved the rarest of things in development work, namely a sustainable outcome. The project is now in the seventh year of its 10-year programme and is on course to end according to plan. Ghana took a bold decision to improve its mental health services despite having extremely limited capacity to do so. The Kintampo Project has been an important addition to the international knowledge base on ways to introduce a new and successful workforce.

\section{References}

Roberts, M. \& Adjase, E. (2013) Summary overview of the Kintampo Project Ghana-Hampshire mental health link. Available at http:// www.thekintampoproject.org/storage/Kintampo \% 20Project \% 20 Illustrated \% 20project \% 20plan.pdf (accessed 25 January 2014).

Roberts, M., Asare, J., Morgan, C., et al (2013) The Mental Health System in Ghana. Ministry of Health, Republic of Ghana.

Stenhouse, L. (1975) An Introduction to Curriculum Research and Development. Heinemann.

\section{Bursaries for psychiatrists from developing countries}

The Faculty of the Psychiatry of Intellectual Disability and the Faculty of the Psychiatry of Old Age both offer annual bursaries for a psychiatrist from a low- or middle-income country (LMIC) to attend their Annual Residential Meetings (ARMs). The recipients of these respective bursaries will give an oral or poster presentation, or deliver a workshop at the meetings. The deadline to apply for the Intellectual Disability ARM bursary is 31 May 2014, and the deadline for applications for the Old Age ARM bursary is 31 October 2014. Please contact Kitti Kottasz (kkottasz@rcpsych.ac.uk) for more information. 